\title{
THE STUDY OF HOMOGENEOUS AND HETEROGENEOUS SENSITIZED CRYSTALS OF CADMIUM SULFIDE. PART IV. FEATURES OF THE REVERSE PHOTOEXCITATION METHOD
}

For the first time, a reverse method of studying the spectral distribution curves of the photocurrent was applied, which allows to separate the contribution of equilibrium and non-equilibrium carriers.

This publication is a continuation of the reviews [1-3]. In order to preserve the generality of the work, the numbering of sections is selected to be general. Numbers of formulas and figures are presented in sections. References to literature in each review are given individually.

Cadmium sulfide crystals are used in our research as a convenient model material. The results obtained on them and the constructed models are also applied to other semiconductor substances.

\subsection{The features of spectral distribution of the photocurrent in terms of the reverse excitation}

In the vast majority of cases, various spectral characteristics of semiconductor samples are measured from small to large wavelengths of light. This is not of fundamental importance in the study of its intrinsic conductivity. However, this is not the case for studying the processes associated with entrapment.

With this method of measurement production, the process of filling-emptying the traps goes with an additional stage. First, when excited by wavelengths from the selfabsorption band, a large concentration of nonequilibrium carriers is created. Some of them settle on the traps. At sufficiently high light intensities and the rate of change in the wavelength of light, it is possible to create conditions under which the trap at the time of its excitation is completely filled with a nonequilibrium charge, regardless of the background of the processes.

This is convenient. In this case, due to a significant release media photo response is greater, which facilitates the definition of the main parameter - the activation energy, i.e. trap depth, the same, of course, as for equilibrium and nonequilibrium charge.

However, it is absolutely impossible to study the processes associated with the concentrations of charge carriers on the traps that existed there initially, before light exposure.
Due to the receipt of a large number of non-equilibrium charges, such processes are completely camouflaged.

Or it is necessary to wait for the relaxation times when each wavelength is illuminated from different points in the spectrum, when the concept of the direction of its change in the direction of increase or decrease becomes meaningless. Each wavelength of light used causes an independent action that is not related to the previous exposure.

In addition, traps that have a small capture cross-section and /or whose concentration in the crystal is insignificant are not able to change the stationary current level and appear only in the first moments of its establishment.

When studying equilibrium processes in a crystal involving traps, it is necessary to apply a reverse change in the wavelength of radiation from large values (usually infrared) to small (visible region) $[4,5]$. In this case, the light acts only as a tool. By exciting carriers from traps, the light only reads the concentration of the captured charge that already existed there.

Note that this creates a rather peculiar situation. Perhaps because of this, this method of changing the spectral composition of excitation is not widely used.

Although carriers transferred by light from the bound state to the free state are by definition non-equilibrium, their concentration, at usually used sufficiently high 
levels of excitation, is uniquely determined by the equilibrium charge that was on the traps before illumination.

Even more complicated is the situation with a system of interacting traps, as in our case, between the main and excited States of R-centers. Consideration of the processes that take place in this case is highlighted in a separate Section 6.2.

With all the nuances of current generation in a semiconductor crystal, the versatility of the reverse method allows measurements to be performed both traditionally in stationary mode and in dynamic mode with different rates of change in the wavelength of exciting light. Classical measurements with a fixed wavelength at each point act as a special case of the dynamic reverse method.

The selection of phenomena that occur in different order of excitation opens up a previously unused opportunity to clarify the nuances of ongoing processes.

Figure 6.1 shows graphs of the photocurrent at various modes and rates of change in the wavelength of exciting light in the visible region. At the edges of the spectrum - at 400 and $900 \mathrm{~nm}$, the crystal was kept for 20 minutes until stationary conditions were reached. Technologically, in all cases, the curve was measured first when the wavelength increased, then when it decreased.

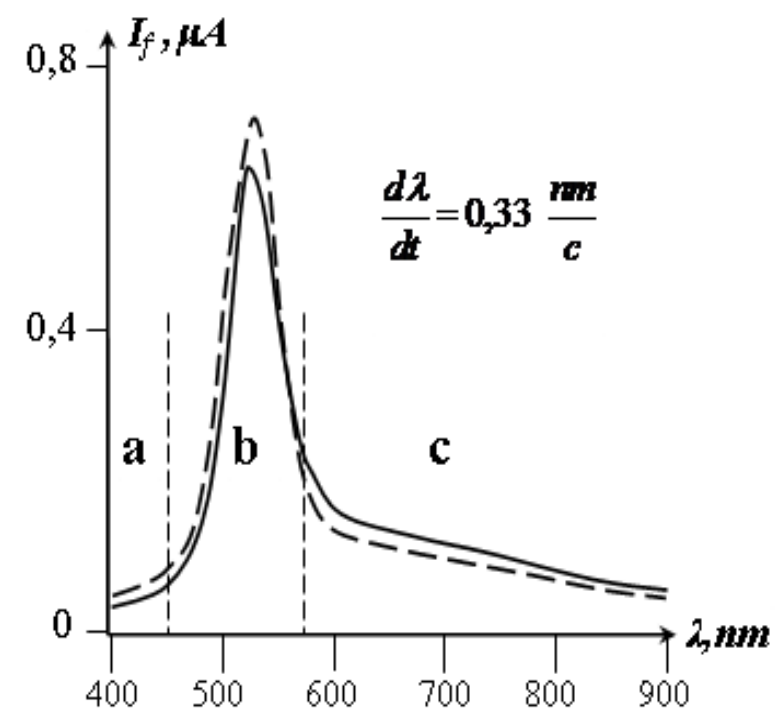

A)

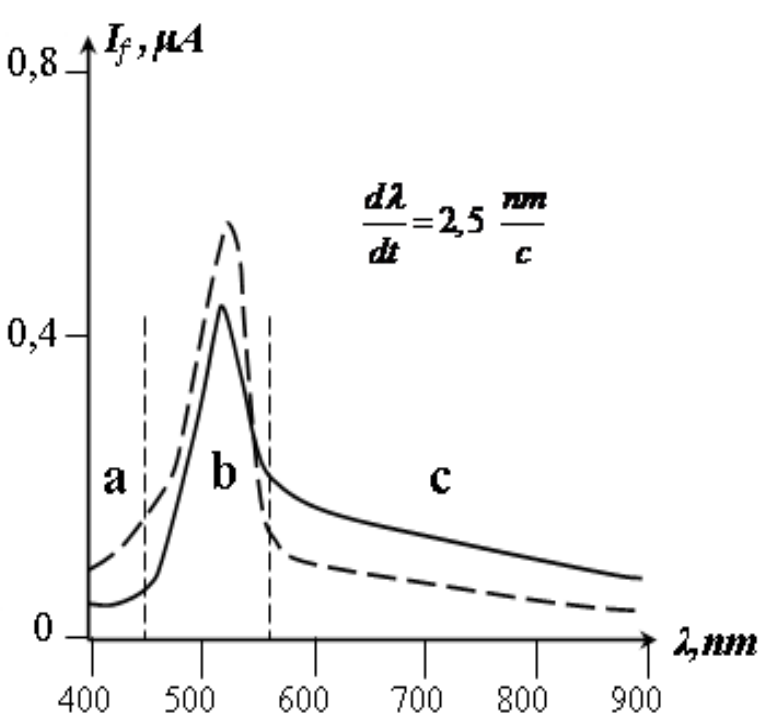

B)

Fig. 6.1. Typical curves of the spectral distribution of the photocurrent of the studied samples when the wavelength changes from small to large values (solid line) and from large to small (dotted line). The speed of change in the wavelength of light: A) $-0.33 \mathrm{~nm} / \mathrm{s}$ and B) $-2.5 \mathrm{~nm} / \mathrm{s}$. в рисунке исправить с на s.

According to the nature of the processes occurring the graphs of the spectral distribution of the photocurrent are divided into three regions:

\section{a) The region of fundamental absorp-} tion, $400-450 \mathrm{~nm}$.

At wavelengths of $400-450 \mathrm{~nm}$, due to the strong absorption of light, the photocurrent is formed mainly in the near-surface layers, despite the fact that under the conditions of our experiment, mainly transverse conductivity was studied. In these conditions, due to the small size of the sample (the interelec- trode distance was less than $1 \mathrm{~mm}$ ), the contact areas begin to play a significant role.

This is where the highest concentration of R-centers is located. The barrier field accumulates them both from the depth of the crystal volume relative to the light flux, and from the near-surface layers of the frontal surface. According to [6,7], $\mathrm{R}$-centers due to their intrinsic charge and field drift inside the lattice tend to accumulate precisely in the SCR of the shut - off contacts at the surface. 
The current flow is controlled by barriers at both edges of the sample. This is supported by further research carried out currentvoltage characteristics.

$\mathrm{R}$-centers play a compensating role in forming the barrier. If the barrier is repulsive for electrons (and in $\mathrm{CdS}$ these are the main carriers), then the accumulation of a positive charge on the R-centers leads to a decrease in the barrier and an increase in the transverse photocurrent. A similar role can be played, depending on the charge state of the R-centers $[6,7,8]$, by reducing the negative charge when holes are captured on them.

In this case, the spectrum $I_{f}(\lambda)$ must be separated. Previous illumination with the energy of photons of the order $E_{g}(\lambda \sim 450 \mathrm{~nm})$ in the conditions of the retracting field, it contributes to filling holes in the R-levels, lowering the barrier and increasing the photocurrent (see Sections 3.1-3.2).

If the excitation first occurs from the side of short wavelengths $\left(\lambda \sim 400 \mathrm{~nm}, \mathrm{E}_{\text {photon }}\right.$ $>E_{g}$ ), then a competing mechanism is activated - due to the above-barrier emission of hot electrons and their tunneling in the narrow upper part of the barrier, the negative charge at the geometric border of the crystal increases, which contributes to the formation of a higher barrier and a smaller photocurrent.

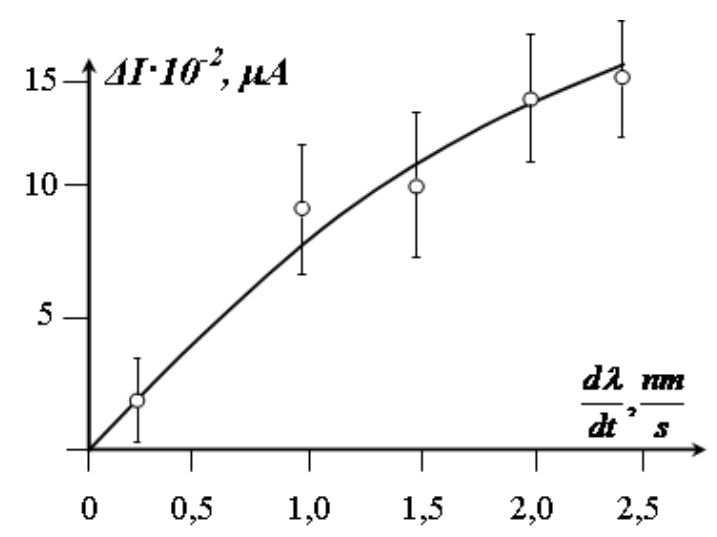

Fig. 6.2. Discrepancy of the short-wave value of the photocurrent for forward and reverse changes in the wavelength of light.

All these processes - both those that lower the barrier and those that increase it take some time to implement. As a result, both the value of the short-wave photocurrent itself and the value of the divergence of graphs in reverse excitation turn out to be dependent on the rate of change in the wavelength.

We observed an almost double increase in the maximum photocurrent at $\lambda \sim 400 \mathrm{~nm}$, if increased from 0,33 to

\section{$2,5 \mathrm{~nm} / \mathrm{s}$ (Fig. 6.1).}

At the same time, the spread of the initial and final values of the photocurrent also increased. Figure 6.2 shows the divergence of the photocurrent graphs for forward and reverse changes in the light wavelength of figure 6.1 in a $400 \mathrm{~nm}$ section. The number of measurements for each applied speed was 5, and the confidence probability was assumed to be 0.95 . It can be seen that the value $\Delta I$ almost linearly increases by more than a dozen times when moving from a rate of 0.33 to $2.5 \mathrm{~nm} / \mathrm{s}$.

Both of these changes are easy to understand, given that if the changes occur quickly, then the process of localization of holes is advantageous, since the barrier field itself contributes to the accumulation of positive charge and the extraction of negative.

On the contrary, with a long - term control experiment (up to 3 hours) with constant illumination $\lambda=400 \mathrm{~nm}$, it was possible to increase the photocurrent from 0.030 to $0.050 \mu \mathrm{A}$.

Note that the revealed regularities are the prerogative of the proposed reverse method and do not appear in stationary measurements.

b) The area of intrinsic absorption, $450-570 \mathrm{~nm}$.

In the area of intrinsic absorption, the number of current carriers that have passed into the free state depends only on the ratio between the energy of the incident photons and the width of the band gap. However, this is not enough to form a photocurrent. As shown in [9], the maximum dependence is $I_{f}(\lambda)$ the current value is defined by the expression $I_{0}=e L \tau_{n} \mu_{n} \frac{b}{c}$, when, - mobility $\mu$, the current-voltage $U$ and geometric dimensions of the sample, - includes the 
lifetime $\tau$. Earlier [8], it was found that the lifetime of the main carriers in the sensed samples can significantly increase (up to five orders of magnitude) if the concentration of charged R-centers is comparable to the existing number of S-centers. This makes the graph view dependent $I_{f}(\lambda)$ from the prehistory of semiconductor excitation. As noted above, the proper absorption remains almost adequate for both directions of change in $\lambda$. However, when the wavelength of light increases to the left of the maximum, the excitation of the semiconductor occurs after activation of the near-surface layers and extraction of holes mainly in the contact areas. The filling of R-centers in the volume of the crystal is relatively small. On the contrary, if the maximum is approached from the right, the preliminary emptying of traps is added to the interzone excitation (see point "c"). This leads to a greater concentration of free holes, an increase in the population of R-centers, and with it, the lifetime of the main carriers.

Indeed, in the vast majority of cases, we observed an increase in the photocurrent in the long-wave part of the graphs in the " $b$ " region of Fig. 6.1.The value of the photocurrent at the maximum was also higher, so there was a slight shift of the graph to the right.

The filling-emptying processes of traps cannot be balanced instantly. In addition, the crystal's sensitivity is based on the interaction between spatially distant $\mathrm{R}$ and $\mathrm{S}$ centers. And that takes time. As a result, the type of dependency changes $I_{f}(\lambda)$ it turned out to be related to the rate of change in the wavelength.

The graph was modified slightly for too high or too low speed. Accordingly, either the process of insensitivity did not have time to be established, or the mechanisms of thermal distribution had time to turn on, etc. The greatest changes in the photocurrent of the studied samples at the applied intensities of

light flows occurred at $\sim 1-2 \mathrm{~nm} / \mathrm{s}$. This is

what determined the choice of the interval of the used rates of change in the wavelength of light in Fig. 6.1.

It should be emphasized that the recorded changes, as for point "a", are due to the applied reverse excitation method and are not available for observation or analysis in traditional stationary measurements.

\section{c) The region of impurity absorp-} tion, $570-900 \mathrm{~nm}$.

The curves of the spectral distribution of the photocurrent after a relatively rapid decrease (by 7 to 10 times) had a well - distinguishable fracture at a wavelength of $550-580 \mathrm{~nm}$. Then, in the longwave region of the spectrum, they were characterized by a slow decrease in the photocurrent in a wide range that exceeds the total width of the first two described regions (Fig. 6.1). As expected, the photocurrent measured with a set wavelength always turned out to be greater than when the excitation wavelength was reduced. Moreover, this discrepancy turned out to

be different for different values

(Fig.

$6.1)$.

The presence of a contribution to the photocurrent when excited by light with wavelengths of $600-900 \mathrm{~nm}$ indicates the presence of deep traps in the samples in the middle and below the middle of the band gap.

Since the most common crystals were used for measurements and no special culling was carried out, they did not have mainly one class of adhesion levels. $\mathrm{Nu}$ merous contributions of traps with different activation energies provided the wide area of impurity conductivity noted above. We deliberately went to this expense in order to demonstrate the advantages of the proposed method on conventional, nonselective samples.

As shown in point "b", in the field of intrinsic sensitivity, the current at the reverse change of the wavelength - from large values to small - on the contrary, was always greater than at the direct change from small to large. For this reason there are graphs on the borders of these areas $I(\lambda \downarrow)$ and $I(\lambda \uparrow)$ always intersected (Fig. 6.1). This effect, which is very convenient for unambiguously separating the region of interband transitions from the impurity excitation, is by definition a feature of the exclusively reversible method and does not 
appear in any way in traditional measurements.

It is recorded that as the growth the intersection point shifts slightly towards shorter wavelengths. This correlates with the fact that $I(\lambda \uparrow)$ for such speeds, it turns out to be higher (see below), which, for a sharp front of the photocurrent decline in the " $b$ " region, should lead to exactly this result for geometric reasons.

Since the detected traps were deep enough, the process of thermal emptying did not play a significant role for them. Thus, subtracting for each wavelength from the forward current $I(\lambda \uparrow)$ return $I(\lambda \downarrow)$, it is easy to get the contribution to the photocurrent of only non-equilibrium carriers (Fig. 6.3).

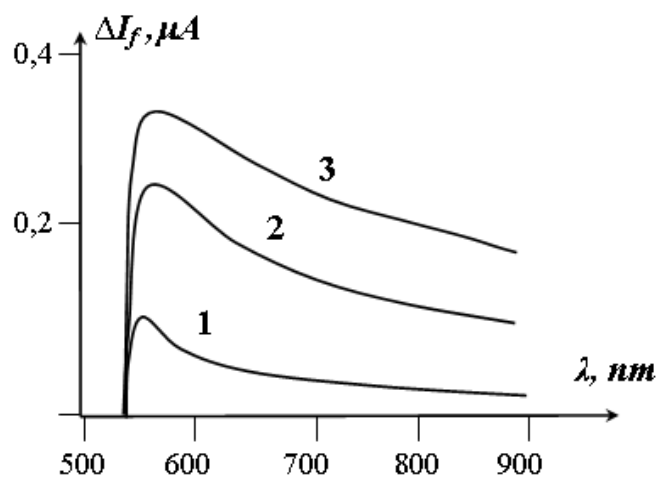

Fig. 6.3. Spectral distribution of the photocurrent signal difference for the speed of light wavelength change: $1-0,33 ; 2-1,5 ; 3$ $-2,5 \mathrm{~nm} / \mathrm{s}$.

As expected, the higher the rate of change in the wavelength, the less time to affect competing processes - additional spontaneous loss of electrons to the capture centers and their relaxation return to equilibrium. As can be seen from Fig. 6.3, the nonequilibrium contribution to the current as it

increases at first, it increased rapidly, and

then it almost stabilized at $2,5 \mathrm{~nm} / \mathrm{s}$. This also served as an additional determinant for selecting the range of values . We can say that in our case, the curve 3 in figure 6.3 already reflects the net value of the non-equilibrium trap contribution. It was possible to observe this value only due to the reverse method.

As can be seen from Fig. 6.3, the curves $\Delta I(\lambda)$ they were characterized by a fast increase at the beginning of the impurity region $(550-570 \mathrm{~nm})$, then a maximum at $570-580 \mathrm{~nm}$ and a prolonged decrees to $900 \mathrm{~nm}$. The first circumstance is provided by the competition noted above on the border with the area of its intrinsic absorption. The second indicates, of course, better retention of the pre-captured charge by deeper traps. The third, as already noted, is the presence of a whole family of other capture traps.

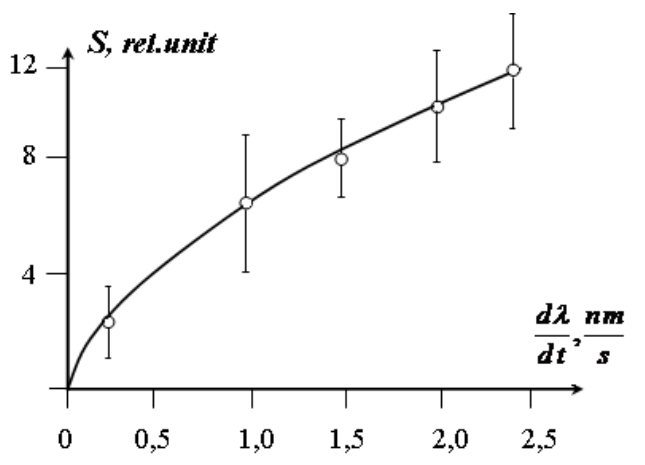

Fig. 6.4. Dependence of the area of divergence of reverse photocurrent graphs in the area of impurity absorption (600-900 $\mathrm{nm}$ ) on the rate of change of the excitation wavelength.

In addition, the curves of the spectral distribution of the contribution to the photocurrent of each of the traps must have an asymmetric maximum. Due to the circumstances already considered, when excited from a large wave length to a small one, the equilibrium charge is mainly ejected from the traps. This is usually characterized by a bell-shaped maximum trap contribution. The samples had a high dark resistance, so the contribution of such a charge could not be significant. On the contrary, when excited from small to large wavelengths (i.e. first, the traps are significantly more pre-filled with a nonequilibrium charge, and second, they are intensively emptied in the short-wave part of the spectrum. When excited by longwave quanta, due to the already reduced 
population, the number of emissions is less. As a result, the difference curve is not symmetrical. The sum of the tighter short-wave tails of the trap maxima may provide the overall maximum of the graphs in figure 6.3 at wavelengths of 550-600 nm.

Total value of the impurity conductivity contribution can be estimated from the area bounded by the curves in figure $6.1 I(\lambda \uparrow)$ and $I(\lambda \downarrow)$ for wavelengths from 600 to $900 \mathrm{~nm}$. At Fig. 6.4 shows how this value changes for different values . To calculate the average value and confidence interval, the measurements were repeated five times. The curve in the figure is obtained using two different methods. First, using the image program Photoshop. Second, the graphs of Fig. 6.1 in the range of wavelengths $550-900 \mathrm{~nm}$ were constructed at the same scale, then a segment of paper was mechanically cut out, bounded along the axis of the abscissus by straight lines $\lambda=550$ and $\lambda=900$, and on the axis of the ordinate curves $I(\lambda \uparrow)$ and $I(\lambda \downarrow)$ and its weight was determined. The results obtained by both methods gave an identical picture, as shown in figure 6.4.

It is characteristic that with the growth of the speed of change in the wavelength of light, the lower limit of the segment $I(\lambda \downarrow)$ changed slightly. The increase in the area of divergence in the area of trap deposits was mainly due to an increase in the values $I(\lambda \uparrow)$.

We interpret this as additional confirmation that in reverse measurement, the contribution to the current is carried out by an equilibrium trap charge. Its value is small for the entire area of applied speeds there is a complete emptying of the traps. The nonequilibrium charge accumulated on the traps after passing the wavelengths of their intrinsic excitation is, of course, much larger, which ensures the predominance of the curve $\mathrm{I}(\lambda \uparrow)$.

This also explains the sublinear nature of the graph Fig. 6.4. at high speeds, the traps do not have time to completely empty.

Note that thanks to the applied method, it is possible for the first time to clearly separate the contribution of an equilibrium and non-equilibrium trap charge.
As follows from the above, it is the reverse method, and with the maximum speed , allows you to best identify both existing electronic traps and some of their features.

\subsection{Reverse spectral characteristics in the region of IR - quenching. The case of interacting traps}

Section 6.1 describes the nuances of filling-emptying traps and the advantages of the reverse excitation method. The situation with a system of interacting traps, as in our case, between the main and excited States of R-centers is even more complicated.

In this case, the long-wave light effect is symmetrical. For any sequence of excitation, the levels are activated in turn. The direction of change in the wavelength: from large to small, or from small to large, determines only the order of activation of the holes - either first they are activated from the shallower excited state, and then from the deep ground state, or Vice versa.

In the latter case, we should also consider the possibility that a part of the IR radiation quanta with an energy of $1.1 \mathrm{eV}$ (for cadmium sulfide) can also excite Rcenters at a depth of 0.9 with the formation of hot free holes.

Comparing traditional stationary measurements for complex traps and the proposed method of operation at different speeds , the following should be noted:

1. First, both of these methods are not antagonistic. On the contrary, the stationary method should be understood as a special case of zero-speed measurements $\frac{d \lambda}{d t}=0$. Features that can be analyzed for other values , they are omitted.

2. A stationary measurement method with an already established photocurrent works well for significantly filled traps with a high concentration. More typical is a small charge accumulated on the traps 
and/or their low concentration. The processes associated with the influence of this component on the formation of photocurrent affect only in the first seconds at the beginning of exposure. No analysis can detect them from the stationary value of the photocurrent, since they are no longer there.

In dynamic measurements, the role of relaxation changes. From a hindering factor, it becomes an ally. For measurements, especially fast ones, with large values $\frac{d \lambda}{d t}$, relaxation phenomena, of course, will affect the behavior of the photocurrent. It is it is possible to identify these mechanisms and, ultimately, the parameters of the traps that form these mechanisms from comparing the results at different values $\frac{d \lambda}{d t}$ (this means with different degrees of relaxation influence).

3. Non-equilibrium carriers, exchanging with the lattice, in a very small order time $10^{-3}-10^{-1} \mathrm{~s}$ [10] they balance their energy with it. As a result, it is completely impossible to separate the contributions to the current of equilibrium and non-equilibrium carriers for stationary measurements. If the dark current is formed solely by the equilibrium component of the charge, then for the light current it is assumed that its value is associated only and exclusively with non-equilibrium charges. This can be justified for high levels of illumination, and serve as a source of inaccuracy at low light levels. As will be shown below, the proposed method of measurement, especially with the maximum possible speeds $\frac{d \lambda}{d t}$, removes this contradiction.

4. In the case of interacting capture traps, as in our case, between the ground and excited state of the R-centers, the processes of charge redistribution must occur fairly quickly, since geometrically this is the same center. Carriers don't need to spend time drifting from one center to another. Note that the nuances of these processes remain unexplored to date. As an effective tool for such research, the method of high-speed measurements can be used $\frac{d \lambda}{d t}$ in the infrared region.
The range of excitation energies used is called the region of interacting traps in the sense that the effect on the R and R' levels is the excitation of a physically unified center, in contrast to the usual situation with different groups of centers, considered in [4,5].

In General, the spectral distribution of the quenching coefficient [5.11] as the excitation wavelength increases $Q(\lambda \uparrow)$ and when it decreases $Q(\lambda \downarrow)$ for different speeds $\begin{gathered}d \lambda \\ d t\end{gathered}$ it was characterized by a certain decrease in the $\mathrm{Q}$ value and a sliding of the short-wave maximum towards smaller wavelengths, and for the long wave-large ones. For a stationary graph, measurements with a relaxation of up to 20 min at each point were used to avoid transients [6,7]. The sample was also kept for a long time in each cycle at the edges of the spectrum at 1000 and $1600 \mathrm{~nm}$ to prevent interference of graphs.

The reverse graphs for the value were chosen as the reference ones $\frac{d \lambda}{d t} \sim 1$ $\mathrm{nm} / \mathrm{s}$, causing the most discernible modifications. The characteristic changes observed on the photocurrent quenching curve over the entire range of used speeds (from 0.33 to $2.5 \mathrm{~nm} / \mathrm{s}$ ) are summarized in table 6.1.

\section{Feature A:}

The value of $Q$ in each of the peaks is proportional to the number embossed light holes, respectively, for short-wave maximum - from the ground state of Rcenters, and for wavelengths from excited. As the wavelength increases in the quenching region, starting from $900 \mathrm{~nm}$, the exciting light first acts on a deeper basic level. The initial filling of this center is the same as for stationary measurements, but the number of activated holes is less, because, depending on the speed $\frac{d \lambda}{d t}$, the total time of exposure to it is less.

Therefore, the value of $Q_{\operatorname{maxl}}(\lambda \uparrow)$ it turns out to be less than the stationary value. If the excitation is carried out from 
long to short waves, the excited state $\mathrm{R}^{\prime}$ is pre-emptied (see Fig. 7.2). Due to an increase in the number of vacancies on it, the flow of thermally excited holes from the ground state increases. As a result, when the wavelength of light decreases to values of the order of 1100 $\mathrm{nm}$, the population of the R-centers is less and the value of $Q_{\max }(\lambda \downarrow)$ it goes down even more. There is an optimal speed when the discrepancy $\Delta Q=Q_{\max l}(\lambda \uparrow)-Q_{\operatorname{maxl}}(\lambda \downarrow)$ the largest according to the model developed in $[4,5]$. In our case it turned out to be about 1 $\mathrm{nm} / \mathrm{s}$. With a further increase in the speed, the discrepancy decreases, since the forward change of $\lambda$ does not have time to excite the state $\mathrm{R}$, and with the reverse $-\mathrm{R}$ '.

\section{Feature B:}

Now the excitation from the side of long waves meets first the undisturbed filling of the States R' and the value of the maximum $Q_{\max 2}(\lambda \downarrow)$ it is determined only by the time of action on the excited States R', which means the speed . In direct measurements, however, with increasing wavelength, another reason is imposed on this [5]. Before this occurred, the excitation of R-States. If Feature $\mathbf{A}$ is characterized by an increase in the thermal flow of holes, now this causes it to decrease. The population of $\mathrm{R}$ ' centers is less, $Q_{\max 2}(\lambda \downarrow)>Q_{\max 2}(\lambda \uparrow)$.

Table 6.1. Analysis of characteristic changes on the graphs of $Q(\lambda)$ for different speeds of changing the wavelength of the quenching light.

\begin{tabular}{|c|c|c|}
\hline $\begin{array}{l}\text { Axis } \\
\text { Praph } \\
\text { maximum }\end{array}$ & $\begin{array}{l}\text { The Ordinate Y } \\
\text { (the amount of damping Q, \%) }\end{array}$ & $\begin{array}{l}\text { Abscissa X } \\
\text { (radiation wavelength } \lambda \text { ) }\end{array}$ \\
\hline 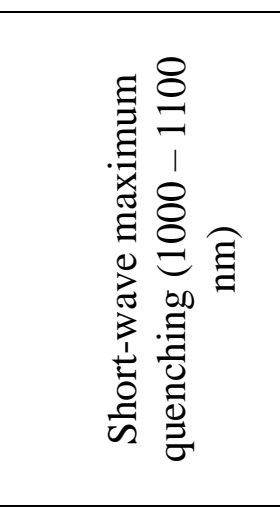 & $\begin{array}{l}\text { A. As the speed increases } \\
\text { discrepancy } \\
\Delta Q=Q_{\max 1}(\lambda \uparrow)-Q_{\max 1}(\lambda \downarrow) \\
\text { increases, reaching the highest } \\
\text { values at about } 1 \mathrm{~nm} / \mathrm{s} \text {, and } \\
\text { then decreases again. }\end{array}$ & $\begin{array}{l}\text { C. Both values } Q_{\max }(\lambda \downarrow) \text { and } \\
Q_{\max 1}(\lambda \uparrow) \text { are shifted towards } \\
\text { short wavelengths relative to } \\
\text { the stationary maximum, but } \\
Q_{\max 1}(\lambda \downarrow) \text { stronger. As the } \\
\text { speed increases these de- } \\
\text { viations first increase, reaching } \\
\text { their greatest values at about } 1 \\
\mathrm{~nm} / \mathrm{s} \text {, and then decrease again. }\end{array}$ \\
\hline 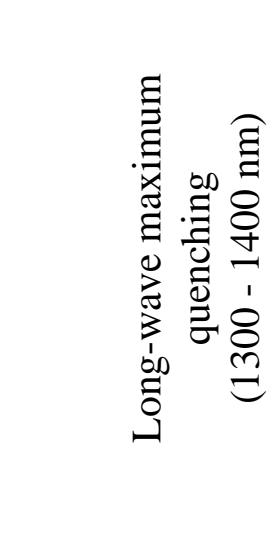 & $\begin{array}{l}\text { B. As the speed increases } \\
\text { discrepancy } \Delta Q=Q_{\max 2}(\lambda \downarrow)- \\
Q_{\max 2}(\lambda \uparrow) \text { increases, reaching } \\
\text { the highest values at about } 1 \\
\mathrm{~nm} / \mathrm{s} \text {, and then decreases } \\
\text { again. }\end{array}$ & $\begin{array}{l}\text { D. Both values } Q_{\max 2}(\lambda \downarrow) \text { and } \\
Q_{\max 2}(\lambda \uparrow) \text { are biased towards } \\
\text { longer wavelengths relative to } \\
\text { stationary } \\
\text { maximum, but } Q_{\max 2}(\lambda \uparrow) \\
\text { stronger. As the speed increas- } \\
\text { es these deviations first } \\
\text { increase, reaching their great- } \\
\text { est values at about } 1 \mathrm{~nm} / \mathrm{s} \text {, and } \\
\text { then decrease again. }\end{array}$ \\
\hline
\end{tabular}


Let's note a characteristic feature. Since it is true for the left maximum $Q_{\max l}(\lambda \uparrow)>Q_{\max }(\lambda \downarrow)$, then, according to the Bolzano - Cauchy theorem, the curves $Q(\lambda \uparrow)$ and $Q(\lambda \downarrow)$ they must intersect. Indeed, at any speed of change in the wavelength of light, at all lighting intensities, we observed

this effect. At the speed $\sim 1 \mathrm{~nm} / \mathrm{s}$ value

$Q \sim 31 \%$ it occurred at a wavelength of 1238 $\mathrm{nm}$, regardless of which way the wavelength changed. Such a nuance is the prerogative of the applied technique and, of course, it is impossible to observe it in principle with traditional measurements.

\section{Feature C:}

Values $Q_{\max }(\lambda \uparrow)$ and $Q_{\max 1}(\lambda \downarrow)$ they sink down in different ways. Plot $Q(\lambda \uparrow)$ it is associated with undisturbed settlement of main state and reflects a simple scaling of a stationary short wave maximum $Q(\lambda)$. Both of its ramps undergo almost the same reduction. The right one is slightly larger, because for measurements with a wavelength greater than the maximum, there is a slight shift in the balance of captures-devastations that the exciting light itself caused during measurements at wavelengths less than $1100 \mathrm{~nm}$. As a result, the maximum $Q_{\max 1}(\lambda \uparrow)$ moves slightly to the left. The pattern changes with measurements as the wavelength of light decreases. As already noted, the excited level was previously emptied. Thermal excitation from the R-centers increased. Their population has decreased. On the long-wave slope of the maximum, this is reflected to a greater extent than on the short-wave, measured later. As a result, the maximum loses its symmetry and depending on the speed

it is mostly shifted to the left. It is obvi-

ous that as the speed of change in the wavelength of light increases, this effect will be weakened, because as the time of exposure to the center decreases, the light manages to knock out fewer holes.

\section{Feature D:}

Similar changes with a shift to the right are formed for the long-wave maximum. Now it's a graph $Q_{\max 2}(\lambda \uparrow)$ subsides asymmetrically due to the fact that the main level was previously emptied, the thermal transfer of holes from $\mathrm{R}$ to $\mathrm{R}$ ' decreased on the left slope. $Q(\lambda \uparrow)$ this reflected more.

Note that all the variety of graph changes was explained using only one mechanism $[4,5]$ - increasing or decreasing, depending on the direction of the change in the wavelength of light, the thermal excitation of holes from the main to the excited states. It is the presence of several simultaneous effects that allows us to consider the existence of such a channel for intra-center redistribution of charge concentrations as proven. The detection was made possible thanks to the use of reversible method of excitation.

\subsection{Features of thermo-optical transitions with excited states of the sensing centers}

Two-level model of A.Rose R.Bube [12,13] qualitatively explains quite well the phenomenon of insensitivity of semiconductors in the presence of slow recombination centers. However, the created model is semifenomenological. Its disadvantages include the following:

I. If localized holes of $\mathrm{R}^{\prime}$ levels were thermally transferred to a free state (Fig. 7.1 B) with an activation energy of $0.2 \mathrm{eV}$, then light quanta with an energy from 0.2 to 0.9 $\mathrm{eV}$ could also release them. In this case, hot holes would simply appear in the valence band. But in this case, the long-wave sensitivity in the range of 1400-1600 nm would not decrease (Fig. 7. 1, feature "a").

II. For the same reason, there would be no cleavage between the maxima of figure 7.1 a, feature " $b$ ". Light quanta in the range from $\lambda_{1}=1100$ to $\lambda_{2}=1400 \mathrm{~nm}$ (from 1,1 to $0,9 \mathrm{eV}$ ) could release media with $\mathrm{R}^{\prime}$ states

III. In the maximum at $1400 \mathrm{~nm}$ (Fig.7.1 A, feature "c"), the value of $\mathrm{Q}$ would be less than in the short-wave (1100 $\mathrm{nm}$ ). This should be done because the centers R and R' have equal capture sections for 
holes, but the level $\mathrm{R}^{\prime}$ is affected by the thermal outflow of carriers. As a result, the stationary population of $\mathrm{R}^{\prime}$ levels would have to be less than for the ground state of $\mathrm{R}$. At the moment of illumination by radiation with an energy of $0.9 \mathrm{eV}$, the picture is blurred by an additional non-equilibrium charge as a result of the transition of holes from $\mathrm{R}$ to $\mathrm{R}$ ' centers. However, both to the right and left of point "c" Fig. 7.1 A $\left(\lambda_{\text {мax }}+\right.$ $\mathrm{d} \lambda$ and $\left.\lambda_{\text {мах }}-\mathrm{d} \lambda\right)$ resonant light excitation of holes does not occur. If the curve $\mathrm{Q}(\lambda)$ smooth (and only such are observed experimentally), then $Q\left(\lambda_{2}\right)$ and in this case, it would be less than $Q\left(\lambda_{1}\right)$.

But even if the Bube model remained true, and the singularity at the maximum $\lambda_{2}$ it simply remained unnoticed by numerous researchers, but its interpretation would still require additional considerations. As shown in $[14,15]$, the intensity of IR light cannot be too significant. For sure observation of the quenching effect, the number of IR photons absorbed should approximately correspond to the concentration of R-centers. Since the capture cross sections $S_{p R}=S_{p R^{\prime}}$, that and IR photons are divided roughly in half between the $\mathrm{R}$ and $\mathrm{R}^{\prime}$ centers. Two photons are required to transit holes first from the $\mathrm{R}$ to the $\mathrm{R}$ '-level, and then to the V-zone. Therefore, even in this case, the long-wave maximum would generally be provided with fewer released holes than the short-wave maximum.

In addition, such processes would require a large amount of time.

IV. If the Fig model were implemented. 7.1B, then there should be an additional maximum quenching with an energy of 0.2 $\mathrm{eV}(\lambda \sim 7500 \mathrm{~nm})$ in the far-IR region when thermal transitions are replaced by optical ones. Moreover, if it is masked by phonon activity, its intensity should increase as the illumination of the crystal increases with its intrinsic light, when the population of $\mathrm{R}^{\prime}$ levels increases. Until now (see, for example, the review [16]), such a maximum of quenching has not been detected.

The height of the quenching maxima in the near-IR region (1100 and $1400 \mathrm{~nm}$ ) decreases as the intrinsic excitation increases according to our data (Fig. 1.1 of Section 1).
V. The symmetry of the quenching maxima at $\lambda_{1}$ and $\lambda_{2}$ indicates against the Bub model (see Fig. 7.1 A). Experimentally, two fairly wide bands are observed, both slightly blurred to the left of the maxima, in the direction of high energies. This is easy to understand if the release of holes from levels $\mathrm{R}$ and $\mathrm{R}^{\prime}$ is carried out directly into the zone. At photon energies exceeding the activation energy of the trap, the holes are able to move to deeper levels in the valence band. Meanwhile, if the Bube model were implemented, the long-wave maximum at $0.9 \mathrm{eV}$ $(\lambda=1400 \mathrm{~nm})$ would have to be an order of magnitude lower than the short-wave one and strictly symmetrical, since the transitions $\mathrm{R} \rightarrow \mathrm{R}^{\prime}$ are essentially resonant.

VI. The same considerations require an almost vertical wall after the second maximum. Photons with an energy less than 0.9 $\mathrm{eV}$ cannot transfer holes from the ground state to the excited state.

VII. If the Bube model works, the distance between the main and excited states of the centers of sensitivity (see Fig. 7.1B), $E_{R}$ $-\mathrm{E}_{\mathrm{R}^{\prime}}=\mathrm{h} v\left(\lambda_{2}\right)=0,9 \mathrm{eV}$. For the room temperature at which the spectrum $\mathrm{Q}(\lambda)$ is taken (Fig.7.1 a), this is 36 times more than the phonon energy $\mathrm{kT}=0.026 \mathrm{eV}$. If we consider that it is the temperature that causes the separation of the excited state of the R' centers from the main one, then this discrepancy seems too fantastic.

VIII. If, according to the Bube model, when illuminated by a light with a wavelength of $\lambda_{2}$, intra-center transitions occur $\mathrm{R}$ $\rightarrow \mathrm{R}^{\prime}$ (рис. 7.1B), then the population of levels R' should increase, and the main states $\mathrm{R}$ - decrease. Experimentally, we observe smooth dependences on the intensity of long-wave light. This indicates that the process follows a single pattern without changing the mechanism over the entire interval. In this case and in high light conditions $\mathrm{p}_{\mathrm{R}^{\prime}}$ $\gg p_{R}$. Due to the large concentration of holes on the centers R', they must be under the quasi-Fermi level. $F_{p}^{*}$ lies in the interval between $E_{R^{\prime}}$ and $E_{v}$. On the other hand, since the population of $\mathrm{pR}$ at high light intensities is low, these levels are above the 
quasi-Fermi level $F_{p}^{*}$ under $E_{R}$. This cannot be done simultaneously, because $E_{R}>E_{R^{\prime}}$ ( see Fig. 7.1B).

IX. The excited state of the trap interacts with the ground state at any temperature [10]. However, in the Bube model, even at $300 \mathrm{~K}$, the R' states exchange holes exclusively with the valence band. And the main level, because of its depth, can at best only capture carriers from there. There is no interaction between levels.

\subsection{An alternative model of phonon-} photon energy absorption in case of holes activated from the centers of slow recombination

The basis for creating a zone model (Fig. 7.1B) served the type of spectral characteristic Q $(\lambda)$ shown on Fig. 7.1 A. However, the presence of two quenching maxima with the same activation energies can be interpreted in a different way [17], as shown in Fig. 7.2.

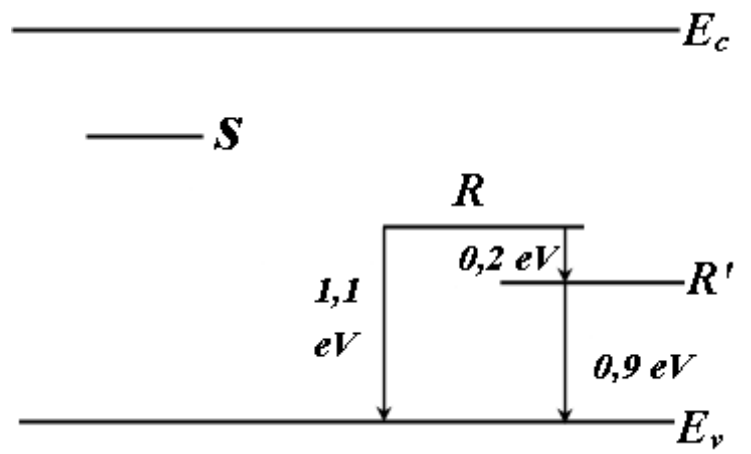

Fig. 7.2. Alternative zone diagram.

This is supported by the following experimental facts:

\section{Relaxation curves.}

A) The Steady-state value of the photocurrent $I_{0}$ (Section 3.4. Fig. 3.7 [2]) is determined by the stationary population of the levels. In full accordance with Fig.1.1 of Section 1.1 [1] for the short-wave maximum $\mathrm{Q}$ at $1100 \mathrm{~nm}$, a smaller photocurrent drop was also observed on the curve 1 of Fig. 3.7.
B) For the same reason, the slope of the graph at $\mathrm{t}=0$ for this curve is less, since it is determined by the number of carriers knocked out, and it is proportional to the concentration of holes located at the Rlevels.

C) In figure 3.7, the time to establish a stationary photocurrent differs by about three times in graph 1 and 2. This is due to the fact that for both wavelengths the damping levels interact with each other. Light with a wavelength of $1100 \mathrm{~nm}$ (Fig. 7.1 a marked $\lambda_{1}$ ) knocks holes out of the main state of R. In this case, the excited state R' performs the function of a damper - part of the holes from it falls on the centers of $R$ and delays relaxation. When activating the $R$ ' levels with a light with a wavelength $\lambda_{2}$, $(1400 \mathrm{~nm}, 1,1 \mathrm{eV})$ the role of the damper goes to the centers of $\mathrm{R}$. Since there are fewer holes, relaxation ends much faster.

Thus, all three features of the relaxation curves indicate that the ground state of the $\mathrm{R}$-centers is less populated (see section 7.1, paragraph III). This corresponds to the level model in figure 7.2.

\section{Migration and relaxation changes. Large interelectrode distance.}

According to the current model in Section 3.1, 3.2 [2], when illuminated by its intrinsic light, under conditions of applied external voltage, charged $\mathrm{R}$-centers migrate from the OPZ contacts to the Central part of the crystal due to diffusion and drift, insensiting it (Fig. 3.4).

Elevated temperatures increase their mobility without changing the charge state. This corresponds to figure 7.2 , since the thermal transitions are intra-center.

An increase in temperature in the Bube model should lead to the emptying of the excited states. Therefore, in the same field, they, on the contrary, would have to move slower.

It is experimentally recorded that IR light $\left(\lambda_{2}\right)$, according to the model of Fig. 7.2, it knocks holes from the most filled R'levels. This inhibits both diffusion and drift. 
On the contrary, if the Bube model were operating (figure 7.1 B), IR light would cause intra-center transitions. The charge state of the R-centers should not change, since the carrier continues to remain within the center. Accordingly, the diffusion and drift would remain the same.

In addition, the depth of R'-levels 0.2 $\mathrm{eV}$ in the model Fig. 7.1 $\mathrm{B}$ is not able to provide long term retention of charge in the dark and accumulation of traps in the SCR.

\section{Migration and relaxation changes. Small interelectrode distance.}

The graph in Fig. 3.3 of Section 3.2. [2] was explained by the migration of charged R-centers. To test this model, the concentration of the charged impurity was artificially reduced by IR radiation with an energy of $0.9 \mathrm{eV}$ (Section 3.3). At the same time, all the features of relaxation disappeared. The photocurrent curve without the formation of a depression reached saturation for long times, several times exceeding the time of reaching the maximum $I_{f}$. Absolute value of the photocurrent $I_{f}$ at the same time, it turned out to be an order of magnitude smaller.

This confirms the viability of the zone diagram 7.2 and is completely inconsistent with the Fig model. 7.1 B for the same reason as stated in paragraph 2 above. in the Bube model, infrared light causes only intracenter transitions.

\section{Lux-ampere dependencies.}

A) Dependence of the quenching coefficient $\mathrm{Q}$ on the intensity of the exciting and quenching light based on the model of Fig. 7.2 is obtained in Section 1.1 [1]. The formula is fully confirmed experimentally. As the number of self-absorbed photons increases, Q decreases, while as the intensity of long-wave light increases, the quenching increases (see figure 1.1 of Section 1.1).

Meanwhile, according to Bube, IR light should only cause transitions from the main to the excited state, and only indirectly, due to temperature, the release of holes into the valence band. A two-step transition would hide the effect of this light on the quenching coefficient.

B) Analysis of the rate of increase of the walls of the quenching maxima also leads to a contradiction with the Bube model. As the number of infrared photons increases, the experimental value of the cleavage between the maxima grows. This is not difficult to understand from Fig. 7.2-photons with energy in the region between maxima from 0.9 to $1.1 \mathrm{eV}$ can be effectively absorbed by both levels.

In the Bube model, this would require creating hot holes in the valence band with an energy from 0.7 to $0.9 \mathrm{eV}$.

In addition, in the Bube model, the longwave wall with $\lambda>\lambda_{2}$ it should not react at all to changes in the intensity of the quenching light, since (see Fig. 7.1 B) photons with an energy less than $0.9 \mathrm{eV}$ are not absorbed at all (see section 7.1, paragraph VI.).

C) In the narrow region of the ratio between the applied field, temperature and intensity of long-wave light with $\lambda_{1} \sim 1100 \mathrm{~nm}$ we were able to create conditions when the first maximum of figure 1.1 a was practically absent ([1] Section 1.2). We explained this by re-grabbing holes. Immediately after activation, the hole is located in the vicinity of the mother center and it is energetically advantageous for it to return back. This is also confirmed by the value of the quantum output for IR light, defined in Section 5.2, at the level of 0.03-0.07. That is, abnormally low.

This fits well with the alternative model and contradicts the Bube model, which assumes a large population of ground states. Accordingly, the probability of capturing holes at these levels, proportional to the number of available places, is much lower. The quantum output can't be small.

D) Dependencies Fig. 5.2 of Section 5.2 [3] for the zone diagram Fig. 7.1 B is not possible. When activated by light with a wavelength of $1100 \mathrm{~nm}$, the hole in this model does not leave the center and therefore no changes from the outside should appear.

The presence of experimental graphs in Fig. 5.2 at different IR radiation intensities confirms the alternative model. 
E) In Section 2.2 [1] it is shown that when the crystal is exposed only to its intrinsic excitation, the Lux-ampere characteristics $I_{f}(L)$ they are linear. With the use of additional infrared illumination, they become superlinear, although at lower absolute values of the current (Fig. 2.2). And this was observed as for the wavelength $\lambda_{1}$, and $\lambda_{2}$ Fig. 7.1 A.

This fully corresponds to the zone diagram in Fig. 7.2. Transitions from both $\mathrm{R}$ and R'-levels are equivalent here. In contrast to the Bube model, where a transition with an energy of $0.9 \mathrm{eV}$ does not lead directly to the release of the hole, and, accordingly, should not give the observed result on the LAC graphs.

\section{Reverse graphs.}

In Section 6.2.the behavior of $q(\lambda)$ graphs under the reverse excitation method is investigated. We compared graphs measured at different rates of change in the wavelength, first in the direction of increasing, and then in the direction of decreasing. The difference is in the order in which the centers are excited.

The Bub model does not involve interaction between levels (see section 7.1, paragraph IX). Therefore, for any method of measurement, regardless of the rate of increase or decrease in the wavelength, the type of maxima $Q(\lambda)$ should not change. Infrared light simply reveals the extent to which holes fill the R and R' levels.

If the levels thermally interact with each other, as in the alternative model, the picture changes. In this case, the impact on one level changes the situation on the other. If the measurements are from a large wavelength of light to a small one, the $\mathrm{R}^{\prime}$ centers are first excited. The transitions of holes from the main states are amplified to the vacant places. Therefore, when the wavelength is reduced to $\lambda_{1}$, due to the smaller filling of the R-centers, the maximum $\mathrm{Q}(\lambda 1)$ will be smaller. Thermal transitions $\mathrm{R} \rightarrow \mathrm{R}^{\prime}$ take time. Therefore the amount of subsidence will depend on the rate of change in the wavelength $\frac{d \lambda}{d t}$. The higher it is, the smaller the change. Thus, in this case, the maximum $Q\left(\lambda_{2}\right)$ turns out to be unchanged, and the maximum $Q\left(\lambda_{1}\right)$ decreases depending on the applied speed $\frac{d \lambda}{d t}$.

If the spectrum is measured traditionally in the direction of increasing the wavelength, the maximum is stable $Q\left(\lambda_{1}\right)$. But it is the effect of light on it during measurements that simultaneously reduces the thermal flow of holes to the $\mathrm{R}^{\prime}$ centers. When the light energy drops to $E_{R^{\prime}}$, there will also be fewer transitions of holes to the free state from it. In this case the maximum is reduced $Q\left(\lambda_{2}\right)$. Moreover, the more time it took to organize thermal transitions from R-levels. That is, the slower the wave length changed, the speed $\frac{d \lambda}{d t}$ was smaller. The alternate subsidence of the maxima $Q(\lambda)$ in the far spectral region, depending on the direction of the wavelength change, is an additional argument in favor of the model Fig. 7.2.

\section{Processes at the short-wave boundary of quenching.}

Section 4 shows [3] that at the shortwave boundary of the quenching region, the $I_{f}$ it does not change, because the intensity of the photoexcitation and quenching processes are equal. Since each of them depends on external influences in different ways - the magnitude of light flows, temperature, applied voltage-then changing these parameters should lead to the creep of the wavelength of the beginning of quenching.

A) We were not able to find any useful changes in the scope of the implemented model $\lambda_{0}$ (Fig. 7.1 A), related to the variation of the voltage applied to the sample or the intensity of its intrinsic light. Increasing your own arousal works equally in both models. This leads to an increase in level filling. When exposed to them, the recoil is higher, the rate of recombination increases, and faster than the rate of photoexcitation at the edge of absorption. Border $\lambda_{0}$ it should be shifted towards shorter wavelengths for both models. 
Indistinguishable results were obtained for different intensities of the infrared light when measuring the spectral dependencies from small to large wavelengths. This is a predictable situation. The greatest impact on the situation $\lambda_{0}$ the spectral region that follows it has an effect $Q\left(\lambda_{1}\right)$. And it is associated with transitions from ground states that work equally in both models.

B) Another thing when measuring $Q(\lambda)$ from large wavelengths to small ones with different speeds (see previous paragraph 5 "Reverse graphs"). In this case, transitions with an energy of $0.9 \mathrm{eV}$ are organized first, and then $1.1 \mathrm{eV}$. Moreover, the higher the light intensity, the brighter the features appear.

If the Bube model works, the $\mathrm{R}$ levels are emptied when pre-lit with a light with an energy of $0.9 \mathrm{eV}$, and when the subsequent excitation of $1.1 \mathrm{eV}$, the photo response from them will be less. Accordingly, the rate of quenching in the area $\lambda_{0}$ decreases. Value $\lambda_{0}$ should move to the right. The higher the speed $\frac{d \lambda}{d t}$, the better it should be shown. First, the population of R-centers does not have time to recover, and secondly, transitions from R-levels due to temperature do not have time to interfere.

The opposite situation was observed experimentally. The higher the speed change the wavelength, the lower limit of the damping $\lambda_{0}$ it shifted towards higher values.

This fully corresponds to the alternative model of Fig. 7.2. Light of $0.9 \mathrm{eV}$ energy empties the R'-centers. The thermal emission of holes $\mathrm{R} \rightarrow \mathrm{R}^{\prime}$ increases because there are more empty spaces on the R'-centers. At the moment of lighting with an energy of $1.1 \mathrm{eV}$, the emission of holes from the Rcenters will be less due to less population. Reducing the rate of recombination also leads to bias $\lambda_{0}$ in the direction of long wavelengths, however, this is already an inertial process, since it includes an additional stage of thermal transitions limited by probabilistic phenomena.

C) The distinction between temperature changes at a fixed voltage and light intensity works Even better. This was shown better when measuring in the direction of increasing the wavelength of the quenching light.

In the Bube model, holes from R'States are knocked out using thermal energy. The population of the main levels does not change. The influence of high $Q\left(\lambda_{1}\right)$ remain stable. A fixed value should be expected $\lambda_{0}$.

In fact, as the temperature increased, it crept away from 920 to $940 \mathrm{~nm}$ (see Fig. 4.2, Section 4 [3]). This happens because the holes are thermally transferred from R to R'levels. Then the lighting with the wavelength $\lambda_{1}$ knocks out fewer carriers. Quenching processes are suppressed, and restoration of equality with the rate of excitation is possible only at large wavelengths.

\section{Oscillation of holes.}

There can be no oscillation of holes at a wavelength of $1100(0.9 \mathrm{eV})$ in the Bube model, since the hole does not transit to the free state at all.

Meanwhile, as can be seen from Fig. 5.1 of Section 5.1 [3], it is for the shortwave maximum that the greatest changes are observed with increasing external voltage. It is in full accordance with the alternative model of Fig. 7.2.

\subsection{Experiment Éntre - Éntre (ei- ther-or). \\ A selective property of the crystal that} allows determining an adequate model between the zone diagrams in the "either-or" mode Fig. 7.1B and 7.2, is the population of the excited states $\mathrm{R}^{\prime}$ when the temperature changes.

In the Bub model [13], the R' levels interact with the $\mathrm{V}$-zone. Heating activates the media from these traps. These are the giving centers. When the temperature increases, the population decreases.

On the contrary, in the alternative model of figure 7.2 , the $\mathrm{R}^{\prime}$-centers interact with the ground States. Phonons activate media from R-levels to R'-levels. Now the traps $R^{\prime}$ are the receiving centers. As the temperature increases, their population increases.

To clarify these circumstances, we used a change in the type of spectral distri- 
bution of the quenching coefficient $Q(\lambda)$ with temperature. The temperature range is selected from room temperature to $50{ }^{\circ} \mathrm{C}$ in order to avoid the phenomena associated with temperature damping of the photocurrent described in [13].

1. The short-wave maximum of this distribution at $1100 \mathrm{~nm}(1.1 \mathrm{eV})$ is determined by transitions from the ground States. In the Bube model, this part of the graph should not change. The R-levels are too deep and cannot be noticeably activated by thermal energy. In the first approximation, their population remains the same.

In practice, the $Q$ values are lower here (Fig. 7.3), which fully corresponds to the expected value for the alternative model.

2. The long-wavelength maximum at $1400 \mathrm{~nm}$ (at $0.9 \mathrm{eV}$ ) increased by about the same amount as the first maximum decreased. Given that the dispersion of the monochromator was equalized not by energy, but by the number of quanta, this indicates in favor of an alternative model Fig. 7.2.

Note that the observed differences were observed only for high IR radiation intensities. We attribute this to the fact that for small light streams, the number of displaced carriers is limited only by the number of photons absorbed. If the number of quanta is comparable and more than the number of traps, the activation processes are determined by the already populated levels and the mechanisms described above take effect.

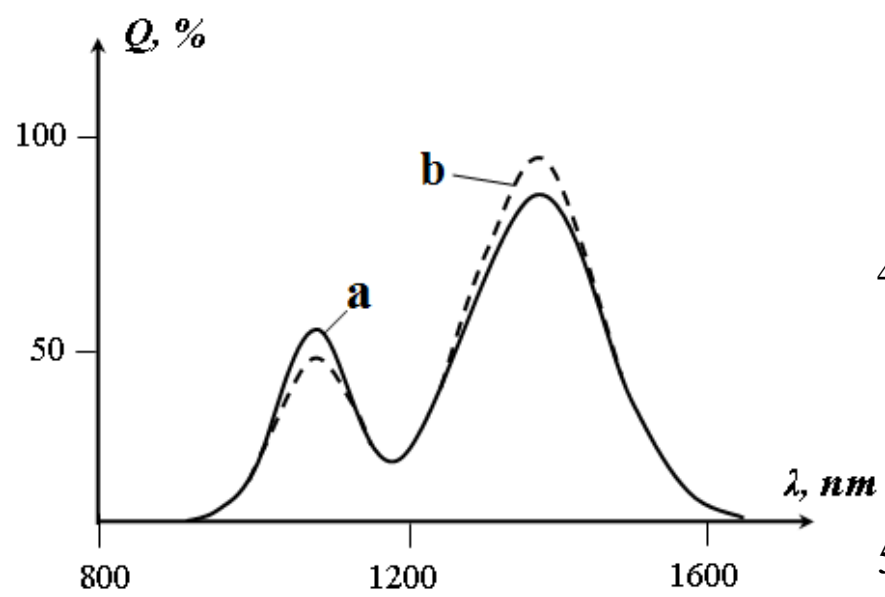

Fig. 7.3. Influence of temperature on the spectral distribution of the quenching coefficient. a) measurements were made at $24{ }^{\circ} \mathrm{C}$; b) - the temperature was $50{ }^{\circ} \mathrm{C}$.
Thus, the created model of thermooptic transitions lacks the disadvantages of the I-IX model R.Bube and confirmed by experimental data 1-7. The scenario of releasing holes from the ground state - through the excited state - to the valence band first involves a transition with phonon absorption $E_{R} \rightarrow E_{R^{\prime}}$ with energy $0,2 \mathrm{eV}$, and only then arousal in a free state $E_{R^{\prime}} \rightarrow E_{v}$ due to the energy of a photon $h v=0,9 \mathrm{eV}$. The zone diagram is implemented in Fig. 7.2.

\section{References}

1. Simanovych N.S., Brytavskyi Ye.V., Kutalova M.I., Borshchak V.A., Karakis Y.N.

The study of heterogeneous sensitized crystals of cadmium sulfide. Part I. About charge state of the centers recombination // "Photoelectronics", n. 26. Odessa, "Одеський національний університет" 2017. s. $124-138$.

2. Kulikov S.S., Brytavskyi Ye.V., Kutalova M.I., Zatovskaya N.P., Borshchak V.A., Konopel'skaya N.V., Karakis Y.N. The study of cadmium sulfide heterogeneously sensitized crystals. Part II. Relaxation characteristics // "Photoelectronics", n. 27. Odessa, "Одеський національний університет" 2018. s. 79 - 93.

3. Kulikov S.S., Brytavskyi Ye.V., , Kutalova M.I., Zatovskaya N.P., Borshchak V.A., Karakis Y.N. The study of cadmium sulfide heterogeneously sensitized crystals. Part III.

Oscillations of excited carriers // "Photoelectronics", n. 28. Odessa, "Одеський національний університет” 2019. s. $133-144$.

4. Бритавський Є., Каракіс Ю. Особливості спектрального розподілу фотоструму в умовах реверсного збудження // Вісник Львівського університету. Серія Фізична. -Львів - 2010. - Випуск 45. - c. $199-205$.

5. Бритавський Є.В., Каракіс Ю.М. Спектральні характеристики напівпровідників із центрами чутливості при реверсному способі збудження // International Conference of Students and Young Scientists in Theoretical and Ex- 
perimental Physics HEUREKA - Lviv 2009. May $20-22$ - Book of abstracts., Ukraine. s. A6.

6. Каракис Ю.Н., Затовская Н.П., Зотов В.В., Куталова М.И. Особенности релаксации фототока в кристаллах сульфида кадмия с запорными контактами // 1-а Українська наукова конференція 3 фізики напівпровідників - Одеса, 1014 вересня 2002. Тези доповідей. Т.2. c. 138

7. Каракис Ю.Н., Борщак В.А., Зотов В.В., Куталова М.И. Релаксационные характеристики кристаллов сульфида кадмия с ИК-гашением // Фотоэлектроника 2002. - вып.11. - с.51 - 55.

8. Britavsky E.V., Karakis Y.N., Kutalova M.I., Chemeresyuk G.G. On the charge state of rapid and slow recombination centers in semiconductors // Photoelectronics. 2008. - n.17. - 2009. - n. 18 s. $65-69$.

9. Чемересюк Г.Г., Каракис Ю.Н. Методические указания к лабораторным работам по спецпрактикуму “Фотоэлектрические процессы в полупроводниках. Часть I" // Одесса. Издательство Одесского национального университета. - 2011. - с. 1 - 59 .

10. Бонч-Бруевич В.Л., Калашников С.Г. Физика полупроводников // М.: Наука, 2007. - с. 220-222.
11. Brytavskyi Ye.V., Karakis Yu.N., Kutalova M.I., Chemeresyuk G.G. Reversive spectral characteristics in IRquenching range of photocurrent. The case of interacting holes // Photoelectronics. $-2010 .-$ n. 19. - s. $56-60$.

12. Роуз А.. Основы теории фотопроводимости // М.:Мир, 1966. - 192 с.

13. Бьюб Р. Фотопроводимость твёрдых тел // М.:Из-во ин.лит, 1992. - c.558 .

14. Драгоев А.А. Визначення квантового виходу інфрачервоного гасіння фототоку // Робота - лауреат Областної сесії Малої Академії наук України. Одеське територіальне відділення. Секція “Фізика". - Одеса 2006. с 32

15. Novikova M.A., Karakis Yu.N., Kutalova M.I. Particularities of current transfer in the crystals with two types of Recombination centers // Photoelectronics - 2005. n.14. s. 58-61.

16. Лашкарёв В.Е., Любченко А.В., Шейкман М.К. Неравновесные процессы в фотопроводниках // К.: Наукова думка, 1981. - с. 264.

17. Mel A.S., Karakis Y.N.. Kutalova M.I., Chemeresjuk G.G. Features of thermo-optical transitions from the recombination centers excited states // Photoelectronics. -2011 . - n. 20. s. $2-27$.

UDC 621.315 .592

Kulikov S.S., Brytavskyi Ye.V., Borshchak V.A., Zatovskaya N.P., Kutalova M.I., Karakis Y.N.

\section{THE STUDY OF HOMOGENEOUS AND HETEROGENEOUS SENSITIZED CRYSTALS OF CADMIUM SULFIDE.} PART IV. FEATURES OF THE REVERSE PHOTOEXCITATION METHOD

For the first time, a reverse method of studying the spectral distribution curves of the photocurrent was applied, which allows to separate the contribution of equilibrium and nonequilibrium carriers.

This publication is a continuation of the reviews [1-3]. In order to preserve the generality of the work, the numbering of sections is selected to be general. Numbers of formulas and figures are presented in sections. References to literature in each review are given individually.

Cadmium sulfide crystals are used in our research as a convenient model material. The results obtained on them and the constructed models are also applied to other semiconductor substances.

Keywords: cadmium sulfide, photoexcitation, photocurrent quenching 
Куликов С. С., Бритавский Е. В, Борщак В. А., Затовская Н. П. Куталова М. И., Каракис Ю. Н.

\title{
ИССЛЕДОВАНИЕ ОДНОРОДНЫХ И ГЕТЕРОГЕННЫХ СЕНСИБИЛИЗИРОВАННЫХ КРИСТАЛЛОВ СУЛЬФИДА КАДМИЯ. ЧАСТЬ IV. ОСОБЕННОСТИ МЕТОДА ОБРАТНОГО ФОТОВОЗБУЖДЕНИЯ
}

\begin{abstract}
Впервые применен обратный метод исследования кривых спектрального распределения фототока, позволяющий разделить вклад равновесных и неравновесных носителей. Данная публикация является продолжением обзоров [1-3]. В целях сохранения общности работы нумерация разделов выбрана общей. Номера формул и рисунков представлены в разделах. Ссылки на литературу в каждом обзоре даются индивидуально. Кристаллы сульфида кадмия используются в наших исследованиях как удобный модельный материал. Полученные на них результаты и построенные модели применимы и к другим полупроводниковым веществам.

Ключевые слова: сульфид кадмия, фотовозбуждение, гашение фототока
\end{abstract}

УДК 621.315 .592

Куликов С.С., Бритавський С.В, Борщак В.А., Затовська Н.П. Куталова М.І., Каракіс Ю.М.

\section{ДОСЛІДЖЕННЯ ОДНОРІДНИХ І ГЕТЕРОГЕННИХ \\ СЕНСЕБЕЛІЗОВАНИХ КРИСТАЛІВ СУЛЬФІДУ КАДМІЮ. ЧАСТИНА IV. ОСОБЛИВОСТІ МЕТОДУ ЗВОРОТНОГО ФОТОЗБУДЖЕННЯ}

Вперше застосований зворотний метод дослідження кривих спектрального розподілу фотоструму, що дозволяє розділити вклад рівноважних і нерівноважних носіїв. Дана публікація є продовженням оглядів [1-3]. 3 метою збереження спільності роботи нумерація розділів обрана загальною. Номери формул і малюнків представлені в розділах. Посилання на літературу в кожному огляді даються індивідуально. Кристали сульфіду кадмію використовуються в наших дослідженнях як зручний модельний матеріал. Отримані на них результати і побудовані моделі застосовні і до інших напівпровідникових речовин.

Ключові слова: сульфід кадмію, фотозбудження, гасіння фотоструму

This article has been received in September 2020/ 